\title{
Stability Study Storage Condition Terminology
}

National Cancer Institute

\section{Source}

National Cancer Institute. Stability Study Storage Condition Terminology. NCI Thesaurus.

Code C96082.

Terminology developed to support Storage Conditions within the Stability Data

Standards. 